\title{
Nucleolin identified by comparative mass-spectra analysis is a potential marker for invasive progression of hepatocellular carcinoma
}

\author{
BIN QIAN $^{1 *}$, YUSHENG YAO $^{2 *}$, YIHONG LIU $^{3}$, MAOLIN YAN $^{4}$, YING HUANG $^{5}$ and YANQING CHEN ${ }^{1}$ \\ ${ }^{1}$ Department of Anesthesiology, People's Hospital Affiliated to Fujian University of Traditional Chinese Medicine, \\ Fuzhou, Fujian 350122; ${ }^{2}$ Department of Anesthesiology, Fujian Provincial Hospital, Fujian Medical University, \\ Fuzhou, Fujian 350001; ${ }^{3}$ Diabetic Center of Control and Prevention, The PLA 520 Hospital, \\ Mianyang, Sichuan 621000; Departments of ${ }^{4}$ Hepatobiliary Surgery and ${ }^{5}$ Pathology, Fujian \\ Provincial Hospital, Fujian Medical University, Fuzhou, Fujian 350001, P.R. China
}

Received August 17, 2013; Accepted March 7, 2014

DOI: $10.3892 / \mathrm{mmr} .2014 .2321$

\begin{abstract}
At present, the diagnosis and prognosis of hepatocellular carcinoma (HCC) metastasis remains poor. Recently, a number of proteins associated with the metastasis and invasion of HCC were identified; however, the effective markers require further elucidation. In the current study, a nucleolin expression was observed in MHCC97L and HCCLM9 HCC cell lines, with low and high metastatic potentials respectively, using comparative proteomics. The data indicated that nucleolin expression in the nucleus was significantly higher in HCCLM9 cells, and it primarily influenced the migration of HCC cells in vitro. Thus, to the best of our knowledge this is the first study to hypothesize that nucleolin may be a novel marker for HCC invasive progression.
\end{abstract}

\section{Introduction}

Hepatocellular carcinoma (HCC) is the third leading cause of cancer-associated mortality worldwide, responsible for $\sim 600,000$ mortalities annually $(1,2)$. The majority of HCC cases occur in developing countries, with $>50 \%$ in China alone $(3,4)$, and the burden of this cancer is expected to increase further in coming years (5). To date, metastasis and recurrence are major causes of the high mortality rate and poor prognosis of tumors, particularly HCC.

Correspondence to: Dr Yanqing Chen, Department of Anesthesiology, Fujian Provincial Hospital, Fujian Medical University, no. 134, Dongjie, Fuzhou, Fujian 350001, P.R. China E-mail: fjslyys@gmail.com

*Contributed equally

Key words: nucleolin, hepatocellular carcinoma, biomarker, electrospray ionization quadrupole time-of-flight mass spectrometry
Surgery remains the primary treatment for HCC, while the incidence of metastatic recurrence following surgical resection remains high (6). Thus, metastatic recurrence is hypothesized to be the primary barrier to the improvement of HCC treatment efficacy (1). Recently, several proteins that are associated with the metastatic recurrence of $\mathrm{HCC}$ were reported $(7,8)$. However, the specific and sensitive biomarkers remain to be elucidated.

In the current study, two human HCC cell lines, HCCLM9 and MHCC97L, with high and low metastatic potentials, respectively, were used to screen differentially expressed proteins. These two cell lines were repeatedly selected in vivo, and were maintained in a similar genetic background with different metastatic behaviors (9-11), providing an ideal cell model for evaluating the novel biomarker of HCC metastasis in vitro $(12,13)$.

The comparative proteomics approach provides a powerful tool to simultaneously analyze hundreds of proteins that are expressed in different cell and tissue samples. This approach is capable of identifying cancer-associated proteins for therapeutic intervention and establishing biomarkers for early diagnosis $(14,15)$.

In the present study, proteins from MHCC97L and HCCLM9 cells were extracted and analyzed by sodium dodecyl sulfate-polyacrylamide gel electrophoresis (SDS-PAGE) coupled with mass spectra (MS) technology. The aim of the present study was to identify a novel candidate biomarker for HCC invasive progression.

\section{Materials and methods}

Cell culture. MHCC97L and HCCLM9 cell lines, were cultured in RPMI-1640 medium supplemented with $10 \%$ fetal bovine serum (FBS; both from Gibco-BRL, Carlsbad, CA, USA) and 100 units $/ \mathrm{ml}$ streptomycin-penicillin at $37^{\circ} \mathrm{C}$ in a humidified atmosphere of $95 \%$ air and $5 \% \mathrm{CO}_{2}$.

Migration assay. The invasion and migration activity of MHCC97L and HCCLM9 cells were assayed using a transwell 
cell-culture chamber as described previously (16). Briefly, cells were seeded into a 6-well plate at a density of $10^{5}$ cells/well. After $24 \mathrm{~h}$ of incubation, the monolayer cells were wounded by scraping a line using a $10 \mu \mathrm{l}$ pipette tip. The real time images of the wound line were recorded using a microscope (Olympus IX71; Olympus Optical Co., Ltd, Tokyo, Japan) at 0, 24 and $48 \mathrm{~h}$.

Protein extraction. The cells were digested with trypsin and collected by centrifuging for $10 \mathrm{~min}$ at $1,500 \mathrm{x}$ g three times. The cell number was quantified using a hemocytometer (VWR Scientific, West Chester, PA, USA). Lysis solution (X5) was added and the mixture was repeatedly freeze-thawed three times in liquid nitrogen. The mixture was sonicated (Model VC50; Sonics \& Materials Inc., Danbury, CT, USA) for 1 sec x 30 on ice. The amplitude of vibration was set as $22 \%$ at room-temperature for $30 \mathrm{~min}$, and finally the mixture was centrifuged at $18,000 \times \mathrm{g}$ for $1 \mathrm{~h}$ at $4^{\circ} \mathrm{C}$. The supernatant was collected and further stored at $-70^{\circ} \mathrm{C}$.

Bradford assay. The staining solution was obtained by diluting the Bradford staining solution with water at a ratio of $1: 4$, and $0,0.28,0.56,0.84,1.12$ and $1.4 \mathrm{mg} / \mathrm{ml}$ of bovine serum albumin were prepared. Next, $100 \mu \mathrm{l}$ diluted standard proteins and samples were mixed with $5 \mathrm{ml}$ diluted staining solution at room temperature for $5 \mathrm{~min}$. Finally, the absorbance, at $595 \mathrm{~nm}$, was detected using an enzyme-linked immunosorbent assay reader (Bio-Rad, Richmond, CA, USA). The standard curve was obtained, and the precise concentration of samples was calculated.

SDS-PAGE analysis. The proteins were mixed with $5 \mathrm{X}$ and $1 \mathrm{X}$ protein loading buffer. The mixture was blotted for $10 \mathrm{~min}$ and immediately placed into ice for $5 \mathrm{~min}$. Samples were loaded onto a $10 \%$ SDS-PAGE gel, and the electrophoresis was performed at $60 \mathrm{~V}$ for $10 \mathrm{~min}$ and $100 \mathrm{~V}$ for $1.5 \mathrm{~h}$. The gel was stained with coomassie brilliant blue (CBB) for $2 \mathrm{~h}$ and then destained with destaining solution.

Tryptic in-gel digestion. Protein spots were excised and transferred into 96-well plates. Gels were destained 1-2 times, and further dehydrated with $100 \mu \mathrm{l}$ acetonitrile (ACN) for $5 \mathrm{~min}$. Next, $50 \mu$ I DTT solution was incubated with the gel particles at $56^{\circ} \mathrm{C}$ for $30 \mathrm{~min}$, and the gel was dehydrated with $100 \mu \mathrm{l} \mathrm{ACN}$ for $5 \mathrm{~min}$. Alkylation of the proteins was achieved by adding $50 \mu 1$ iodoacetamide (IOA), and dehydration was performed with $100 \mu \mathrm{l} \mathrm{ACN}$ for $5 \mathrm{~min}$. The gels were incubated with $15-20 \mu \mathrm{l} \operatorname{trypsin}(0.01 \mu \mathrm{g} / \mu \mathrm{l})$ at $4^{\circ} \mathrm{C}$ for $30 \mathrm{~min}$, and $15-20 \mu \mathrm{l}$ trypsin buffer $\left(25 \mathrm{mM} \mathrm{NH} \mathrm{HCO}_{3}\right)$ was added following complete absorption of trypsin at $37^{\circ} \mathrm{C}$ overnight. Peptides were extracted using solution I at $40^{\circ} \mathrm{C}$ for $1 \mathrm{~h}$ and solution II at $40^{\circ} \mathrm{C}$ for $1 \mathrm{~h}$. Finally, the extracted solution was combined and evaporated.

Electrospray ionization quadrupole time-of-flight mass spectrometry (ESI-Q-TOF). The MS data were obtained using a Q-TOF mass spectrometer (Micromass, Manchester, UK) fitted with an ESI source (Waters Corporation, Milford, MA, USA). The MS/MS data were processed using MassLynx software (Waters Corporation), and Version 2.3 (Matrix Science,
London, UK) was used to search the database. A database search was performed using the following parameters: Database, Swiss-Prot; mass tolerance, \pm 0.1 Dalton (Da); MS/MS tolerance, $\pm 0.05 \mathrm{Da}$; taxonomy, Homo sapiens; enzyme, trypsin; and an allowance of one missed cleavage. In addition, variable modifications of methionine oxidation and fixed modifications of cysteine carbamidomethylation were allowed.

Semi-quantitative RT-PCR. Semi-quantitative RT-PCR was used to confirm the differential expression of selected proteins at the mRNA level. Total RNA was extracted with TRIzol reagent (Invitrogen Life Technologies, Carlsbad, CA, USA), and RT-PCR was performed with a PCR kit from Fermentas (Hanover, MD, USA). The primers used were as follows: Sense: 5'-GGTGGTCGTTTCCCCAACAAA-3' and antisense: 5'-GCCAGGTGTGGTAACTGCT-3' for NCL (136 bp); and sense: 5'-GGAGTCCACTGGCGTCT -3' and antisense: 5'-CATCATATTTGGCAGGTTTT-3' for GAPDH (482 bp). GAPDH was used for normalization. The PCR profile was as follows: $94^{\circ} \mathrm{C}$ for 2 min followed by 30 cycles of $94^{\circ} \mathrm{C}$ for $30 \mathrm{sec}, 48^{\circ} \mathrm{C}$ for $30 \mathrm{sec}$, and $72^{\circ} \mathrm{C}$ for $30 \mathrm{sec}$, with a final extension at $72^{\circ} \mathrm{C}$ for $7 \mathrm{~min}$.

Statistical analysis. The data are presented as the mean \pm standard deviation. Statistical analysis was performed using Prism 5.0 software (GraphPad Software Inc., San Diego, CA, USA). Two-group comparisons of continuous variables were performed using Student's t-test. $\mathrm{P}<0.05$ was considered to indicate a statistically significant difference.

\section{Results}

HCCLM9 cells exhibit a greater migration ability compared with MHCC $97 \mathrm{~L}$ cells. The migration activity of MHCC97L and HCCLM9 cells were evalated by a wound healing assay. The real time images of cell migration were recorded using a microscope at 0, 24 and $48 \mathrm{~h}$. As shown in Fig. 1A, MHCC97L cells did not present a marked migration ability, nevertheless, HCCLM9 cells primarily exhibited migration at $24 \mathrm{~h}$, and the wound was healed at $48 \mathrm{~h}$ (Fig. 1B). These findings suggested that the migration ability of HCCLM9 cells was significantly stronger than MHCC97L cells.

Protein separation using SDS-PAGE (Fig. 2). Following confirmation of the differential migration abilities of MHCC97L and HCCLM9 cells, the proteins that are responsible for migration were investigated. Nuclear and cytoplasmic proteins were, respectively, extracted from MHCC97L and HCCLM9 cells, and the concentration of the proteins was obtained using a Bradford assay (Fig. 2B). Then, $50 \mu \mathrm{g}$ proteins were loaded onto the $10 \%$ SDS-PAGE gel and the proteins were separated at $60 \mathrm{~V}$ for $20 \mathrm{~min}$ and $100 \mathrm{~V}$ for $1.5 \mathrm{~h}$. The gel was stained with $\mathrm{CBB}$ and the differential protein bands were analyzed (Fig. 2A). As shown in Fig. 2C, these differentially stained bands were quantified using gray scale. Finally, two bands were cut out, and the peptides of these proteins were extracted and identified using ESI-Q-TOF MS/MS, as described previously.

Differential protein identification using ESI-Q-TOF MS/MS. The peptides of proteins were dissolved in $18 \mu \mathrm{l} 50 \% \mathrm{ACN}$. 
A
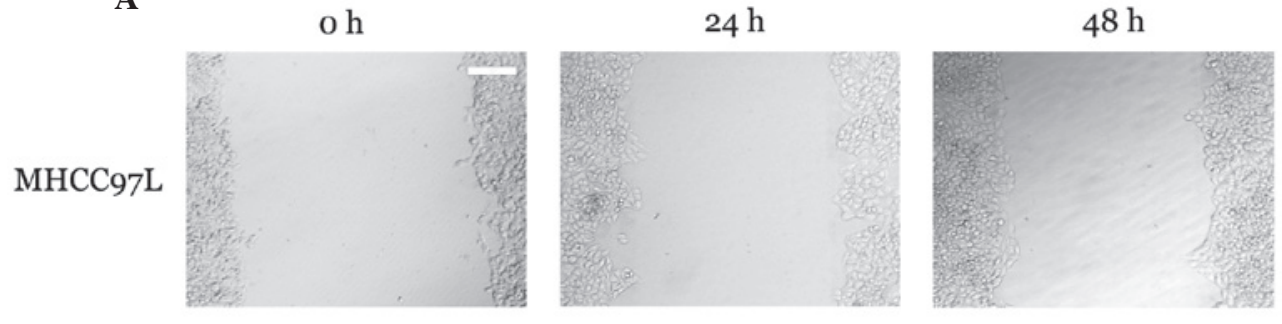

B
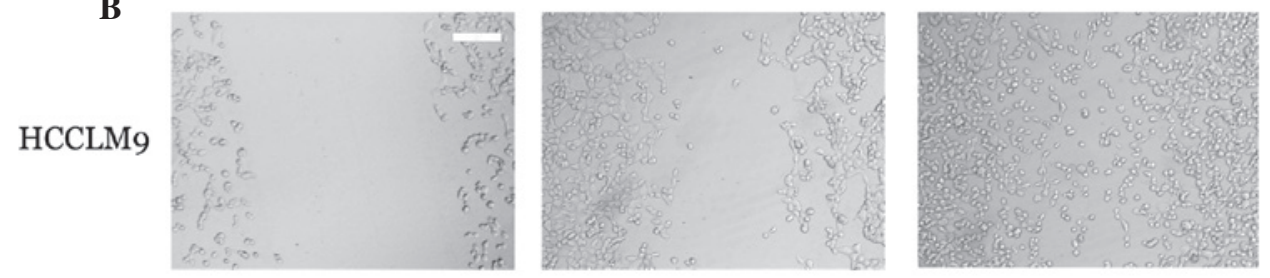

Figure 1. Migration activity of MHCC97L and HCCLM9 cells using a wound healing assay. (A) Representative images of the cell migration in MHCC97L cells at 24 and $48 \mathrm{~h}$, respectively. No migration occurred in these cells. (B) Representative images of the cell migration in HCCLM9 cells at 24 and $48 \mathrm{~h}$, respectively. The cells showed marked migration ability and the wound had healed at $48 \mathrm{~h}$.

A

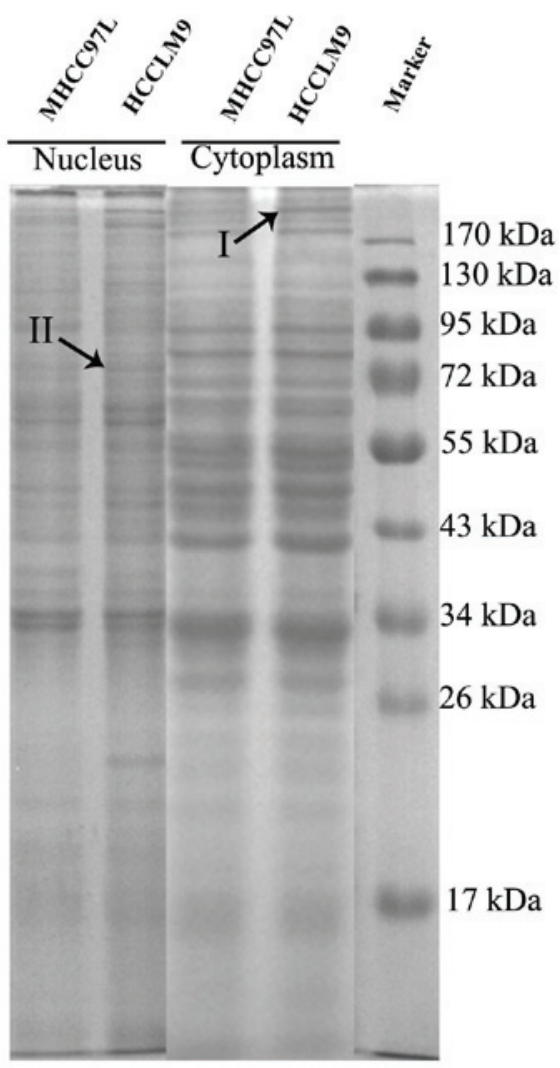

B

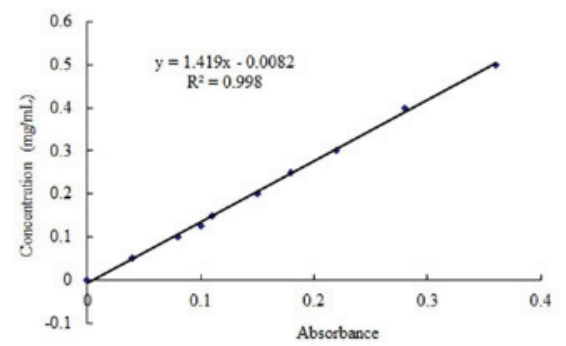

C

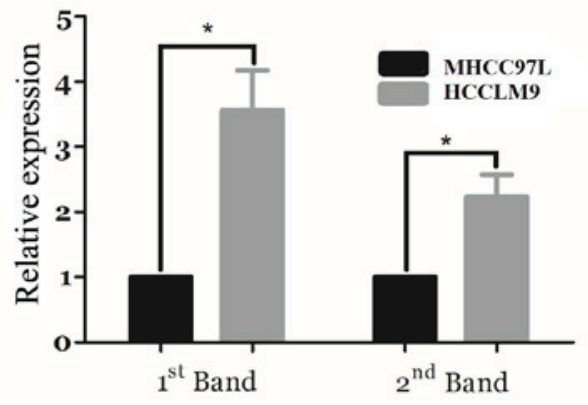

Figure 2. Separation of total proteins by sodium dodecyl sulfate-polyacrylamide gel electrophoresis (SDS-PAGE). (A) Total proteins were separated by SDS-PAGE and stained with coomassie brilliant blue, the gel was scanned and analyzed by ImageScan, and two differential bands were found. (B) Protein concentrations were determined by Bradford assay and the standard curve was formulated. (C) The two different bands were quantified by gray scale, band 1 and 2 are brighter in HCCLM9 compared with MHCC97L cells, ${ }^{*} \mathrm{P}<0.01$.

The top 10 most abundant ions for each MS scan were selected for MS/MS analysis with a data-dependent mode. As shown in Fig. 3, the samples presented an excellent MS/MS image, suggesting that these MS/MS data were of dependable quality, thus, the proteins were identified accurately. In addition, the peptides of trypsin and keratin were automatically excluded.
The MS/MS data were processed using MassLynx software (Waters Corporation). The identified proteins are shown in Fig. 3.

Validation using semi-quantitative RT-PCR. To confirm the differential expression of an identified protein at the 
A

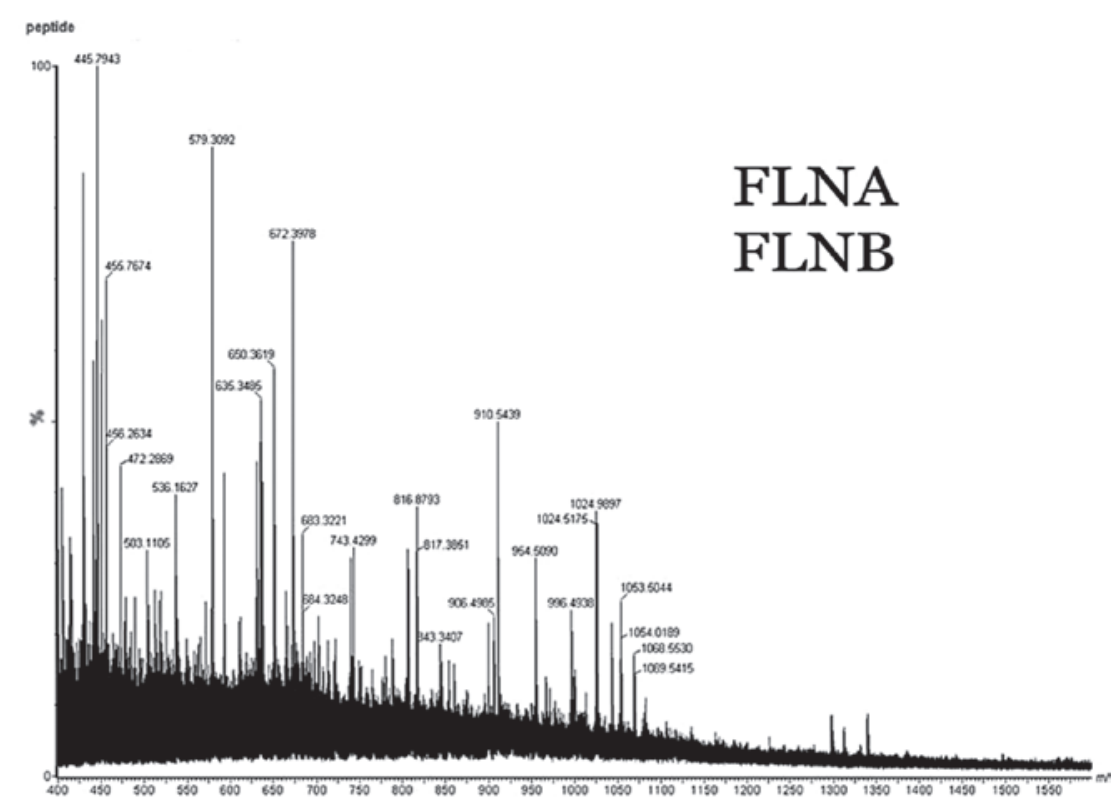

B

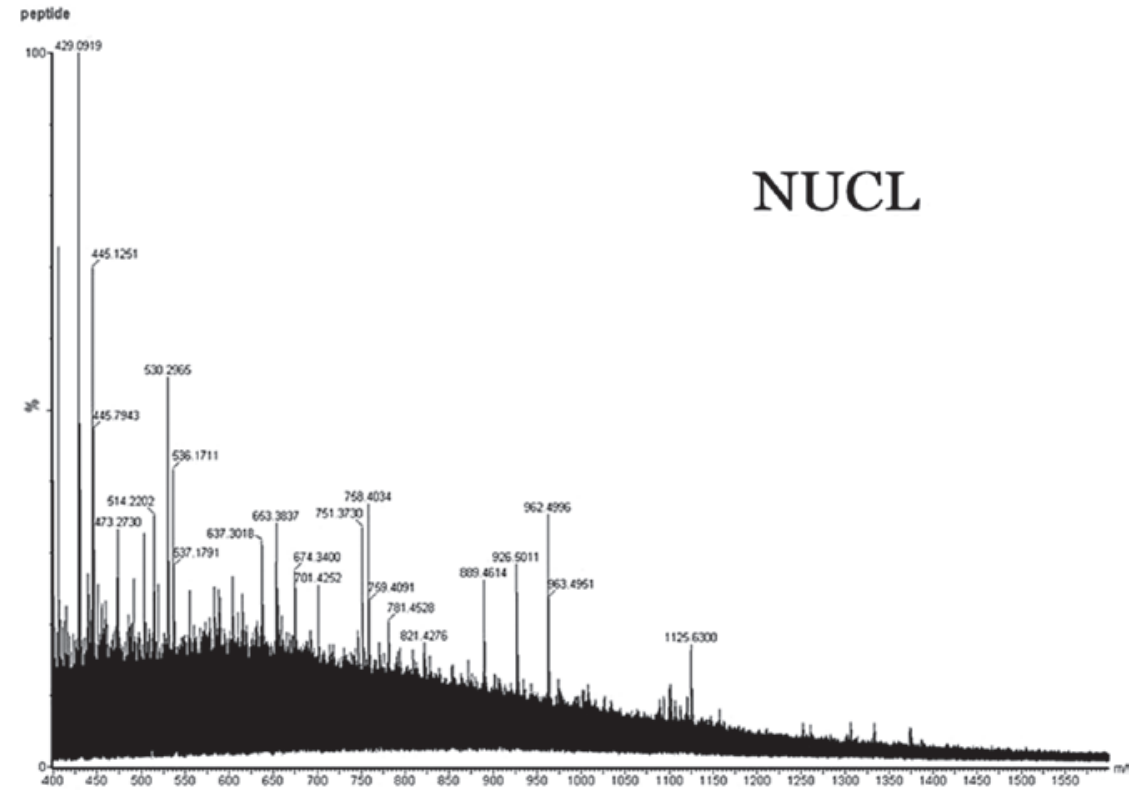

Figure 3. MS/MS spectra image of identified proteins. (A) The MS/MS spectra of FLNA and FLNB. (B) The MS/MS spectra of NUC. FLNA, filamin A- $\alpha$ FLNB filamin B- $\beta$, NUCL, nucleolin.

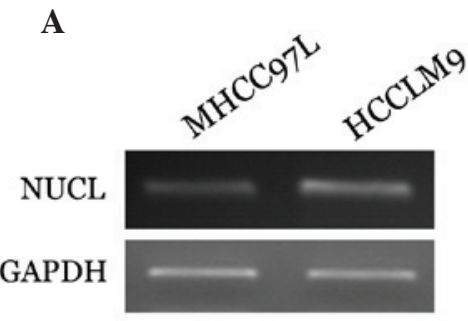

B

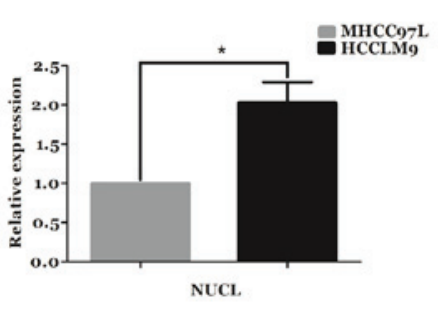

Figure 4. Expression of NUCL in MHCC97L and HCCLM9 cells. (A) NUCL expression was verified by reverse transcription-polymerase chain reaction at the mRNA level, normalized to the expression level of GAPDH. (B) The average intensity of each electrophoresis band was obtained from three independent experiments, the relative expression level of NUCL in MHCC97L and HCCLM9 cells was quantified using Quantity-One software. ${ }^{*} \mathrm{P}<0.01$. NUCL, nucleolin. 
mRNA level, nucleolin mRNA expression was detected using semi-quantitative RT-PCR, and GAPDH was used as an internal control. As shown in Fig. 4A, the mRNA expression of nucleolin significantly increased in HCCLM9 cells, and the relative expression of nucleolin at mRNA level was indicated in Fig. 4B. These findings indicated that nucleolin is also overexpressed in HCCLM9 cells at the mRNA level, suggesting that nucleolin may be a candidate biomarker for the progression of HCC invasion.

\section{Discussion}

Hepatocellular carcinoma (HCC) is the most predominant type of liver cancer in most countries, and the majority of cases of $\mathrm{HCC}$ are associated with chronic hepatitis B virus (HBV) or hepatitis C virus (HCV) infections (17). There are $>500,000$ new cases diagnosed worldwide annually and the incidence of HCC is expected to increase further in the next decade (5). Thus, accurate diagnosis and treatment are critical for HCC patients, particularly for patients with metastatic HCC. A previous study demonstrated that $\alpha$-fetoprotein (AFP) determination lacks adequate sensitivity and specificity for effective surveillance of HCC (18). Indeed, the lack of good early diagnostic markers has rendered this disease a major challenge. Previous studies have investigated certain molecules associated with the progression and metastasis of HCC, including transforming growth factor- $\beta 1$ (TGF $\beta$ ) (19), insulin-like growth factor II (IGF-II) (20), the human cervical cancer oncogene (HCCR) (21), FLNA and PGK1 (8). However, these biomarkers are not adequately specific and sensitive. Thus, the specific diagnostic biomarkers for metastatic progression of HCC require further investigation.

It was previously reported that the metastatic recurrence of HCC is accompanied by numerous molecular alterations (22). Therefore, global profiling of metastatic progression of HCC may aid the development of novel therapeutic targets and identification of diagnostic biomarkers, and is likely to improve the diagnosis and treatment of metastatic HCC.

In the present study, SDS-PAGE-coupled MS/MS technology was used to identify differentially expressed proteins in MHCC97L and HCCLM9 cells. In total, three proteins were identified in two bands, namely FLNA, FLNB and nucleolin. Among these proteins, a novel nuclear protein, nucleolin, was identified from band 2, and it was observed to be overexpressed in HCCLM9 cells. The differential expression of nucleolin was further confirmed at the mRNA level. Thus, the current data suggested that nucleolin was overexpressed in HCCLM9 cells at protein and mRNA levels.

Notably, the present study identified differential expression of FLNA and FLNB in the cytoplasmic proteins, which is consistent with findings reported by Ai et al (8). Aside from the two proteins in the cytoplasm, nucleolin was the only differentially expressed protein among the proteins isolated from the nucleus, and it provided a novel candidate for the diagnosis and treatment of HCC. Furthermore, it was reported that nucleolin may be key in cell proliferation (23-25). Nucleolin induced chromatin decondensation by binding to histone $\mathrm{H} 1$, and it was hypothesized to be involved in pre-rRNA transcription and ribosome assembly (26). Additionally, nucleolin may exhibit a role in the process of transcriptional elongation (26).
In conclusion, to the best of our knowledge the current study was the first to show that nucleolin was overexpressed in HCCLM9 cells at the protein and mRNA level. It was proposed that nucleolin is a novel potential biomarker for the metastasis of HCC and a possible therapeutic target for the treatment of $\mathrm{HCC}$ patients.

\section{References}

1. Ding SJ, Li Y, Tan YX, Jiang MR, Tian B, Liu YK, Shao XX, Ye $\mathrm{SL}, \mathrm{Wu} \mathrm{JR}$, Zeng R, et al: From proteomic analysis to clinical significance: overexpression of cytokeratin 19 correlates with hepatocellular carcinoma metastasis. Mol Cell Proteomics 3: 73-81, 2004.

2. Altekruse SF, McGlynn KA and Reichman ME: Hepatocellular carcinoma incidence, mortality, and survival trends in the United States from 1975 to 2005. J Clin Oncol 27: 1485-1491, 2009.

3. El-Serag HB and Rudolph KL: Hepatocellular carcinoma: epidemiology and molecular carcinogenesis. Gastroenterology 132: 2557-2576, 2007.

4. Parkin DM, Bray F, Ferlay J and Pisani P: Global cancer statistics, 2002. CA Cancer J Clin 55: 74-108, 2005.

5. Venook AP, Papandreou C, Furuse J and de Guevara LL: The incidence and epidemiology of hepatocellular carcinoma: a global and regional perspective. Oncologist 15 (Suppl 4): 5-13, 2010.

6. Llovet JM, Burroughs A and Bruix J: Hepatocellular carcinoma. Lancet 362: 1907-1917, 2003.

7. Wu L, Peng CW, Hou JX, Zhang YH, Chen C, Chen LD and Li Y: Coronin-1C is a novel biomarker for hepatocellular carcinoma invasive progression identified by proteomics analysis and clinical validation. J Exp Clin Cancer Res 24: 29:17, 2010.

8. Ai J, Huang H, Lv X, Tang Z, Chen M, Chen T, Duan W, Sun H, Li Q, Tan R, et al: FLNA and PGK1 are two potential markers for progression in hepatocellular carcinoma. Cell Physiol Biochem 27: 207-216, 2011.

9. Tian J, Tang ZY, Ye SL, Liu YK, Lin ZY, Chen J and Xue Q: New human hepatocellular carcinoma (HCC) cell line with highly metastatic potential (MHCC97) and its expressions of the factors associated with metastasis. Br J Cancer 81: 814-821, 1999.

10. Li Y, Tang ZY, Ye SL, Liu YK, Chen J, Xue Q, Chen J, Gao DM and Bao WH: Establishment of cell clones with different metastatic potential from the metastatic hepatocellular carcinoma cell line MHCC97. World J Gastroenterol 7: 630-636, 2001.

11. Li Y, Tang Y, Ye L, Liu B, Liu K, Chen J and Xue Q: Establishment of a hepatocellular carcinoma cell line with unique metastatic characteristics through in vivo selection and screening for metastasis-related genes through cDNA microarray. J Cancer Res Clin Oncol 129: 43-51, 2003

12. Li Y, Tian B, Yang J, Zhao L, Wu X, Ye SL, Liu YK and Tang ZY: Stepwise metastatic human hepatocellular carcinoma cell model system with multiple metastatic potentials established through consecutive in vivo selection and studies on metastatic characteristics. J Cancer Res Clin Oncol 130: 460-468, 2004.

13. Li Y, Tang ZY, Tian B, Ye SL, Qin LX, Xue Q and Sun RX: Serum CYFRA 21-1 level reflects hepatocellular carcinoma metastasis: study in nude mice model and clinical patients. J Cancer Res Clin Oncol 132: 515-520, 2006.

14. Holly MK, Dear JW, Hu X, Schechter AN, Gladwin MT, Hewitt SM, Yuen PS and Star RA: Biomarker and drug-target discovery using proteomics in a new rat model of sepsis-induced acute renal failure. Kidney Int 70: 496-506, 2006.

15. Kabuyama Y, Resing KA and Ahn NG: Applying proteomics to signaling networks. Curr Opin Genet Dev 14: 492-498, 2004.

16. Zhang K, Ye C, Zhou Q, Zheng R, Lv X, Chen Y, Hu Z, Guo H, Zhang Z, Wang Y, Tan R and Liu Y: PKD1 inhibits cancer cells migration and invasion via Wnt signaling pathway in vitro. Cell Biochem Funct 25: 767-774, 2007.

17. El-Serag HB: Epidemiology of viral hepatitis and hepatocellular carcinoma. Gastroenterology 142: 1264-1273, 2012.

18. Lok AS, Sterling RK, Everhart JE, et al; HALT-C Trial Group: Des-Gamma-carboxy prothrombin and alpha-fetoprotein as biomarkers for the early dection of hepatocellular carcinoma. Gastroenterology 138: 493-502, 2010.

19. Feng Y and Walsh CA: The many faces of filamin: a versatile molecular scaffold for cell motility and signalling. Nat Cell Biol 6: 1034-1038, 2004. 
20. Bedolla RG, Wang Y, Asuncion A, Chamie K, Siddiqui S, Mudryj MM, Prihoda TJ, Siddiqui J, Chinnaiyan AM, Mehra R, de Vere White RW and Ghosh PM: Nuclear versus cytoplasmic localization of filamin A in prostate cancer: immunohistochemical correlation with metastases. Clin Cancer Res 15: 788-796, 2009.

21. Bourguignon LY, Gilad E and Peyrollier K: Heregulin-mediated ErbB2-ERK signaling activates hyaluronan synthases leading to CD44-dependent ovarian tumor cell growth and migration. J Biol Chem 282: 19426-19441, 2007.

22. DayanF, Roux D,Brahimi-Horn MC,Pouyssegur J and MazureNM: The oxygen sensor factor-inhibiting hypoxia-inducible factor-1 controls expression of distinct genes through the bifunctional transcriptional character of hypoxia-inducible factor-1alpha. Cancer Res 66: 3688-3698, 2006.
23. González V and Hurley LH: The C-terminus of nucleolin promotes the formation of the c-MYC G-quadruplex and inhibits c-MYC promoter activity. Biochemistry 49: 9706-9714, 2010.

24. Abdelmohsen $\mathrm{K}$ and Gorospe $\mathrm{M}$ : RNA-binding protein nucleolin in disease. RNA Biol 9: 799-808, 2012.

25. Tajrishi MM, Tuteja R and Tuteja N: Nucleolin: the most abundant multifunctional phosphoprotein of nucleolus. Commun Integr Biol 4: 267-275, 2011.

26. Parada CA and Roeder RG: A novel RNA polymerase II-containing complex potentiates Tat-enhanced HIV-1 transcription. Embo J 18: 3688-3701, 1999. 